\title{
Health Training Needs at Primary Care Level Health Facilities in Rural Western Uganda
}

\author{
Peter Chris Kawungezi1 ${ }^{*}$, Moses Ntaro1, Geren Stone², Daniel A. Guiles 3 , Jessica Kenney², \\ Shem Bwambale4, Michael Matte', Andrew Christopher Wesuta1, David Santson Ayebare1, \\ Moses Wetyanga4, Stephen Baguma1, Fred Bagenda1, Edgar Mugema Mulogo'
}

\footnotetext{
${ }^{1}$ Department of Community Health, Mbarara University of Science and Technology, Mbarara, Uganda

${ }^{2}$ Centre for Global Health, Massachusetts General Hospital, Boston, MA, USA

${ }^{3}$ Departments of Internal Medicine and Pediatrics, Vanderbilt University Medical Center, Nashville, TN, USA

${ }^{4}$ Bugoye Health Centre III, Kasese Local Government, Kasese, Uganda

Email:^pkawungezi@yahoo.com,mntaro@must.ac.ug, gstone@partners.org, daniel.a.guiles@vumc.org, jkenney4@partners.org, shembwambale@yahoo.com, mattemichael18@gmail.com,wesandc@gmail.com, ayebaredavid@gmail.com, moswetyanga@gmail.com,bagumastephen3@gmail.com,bagendaf@gmail.com,emulogo2000@gmail.com
}

\begin{abstract}
How to cite this paper: Kawungezi, P.C., Ntaro, M., Stone, G., Guiles, D.A., Kenney, J., Bwambale, S., Matte, M., Wesuta, A.C., Ayebare, D.S., Wetyanga, M., Baguma, S., Bagenda, F. and Mulogo, E.M. (2020) Health Training Needs at Primary Care Level Health Facilities in Rural Western Uganda. Open Journal of Preventive Medicine, 10, 83-94.
\end{abstract}

https://doi.org/10.4236/ojpm.2020.106006

Received: April 13, 2020

Accepted: June 1, 2020

Published: June 4, 2020

Copyright $\odot 2020$ by author(s) and Scientific Research Publishing Inc. This work is licensed under the Creative Commons Attribution International License (CC BY 4.0).

http://creativecommons.org/licenses/by/4.0/

\begin{abstract}
Introduction: Continual education is recognized worldwide as a tool for the professional development of health care practitioners. It is however effective when the training targets the appropriate needs of the target beneficiaries. This study was therefore aimed at identifying priority training needs of Primary Care Level health professionals in rural Western Uganda. Methods: This was a descriptive cross-sectional survey among 35 rural community health facilities represented by their managers in rural Western Uganda. Participants were invited to Mbarara University of Science and Technology and responded to a self-administered questionnaire and also participated in qualitative group discussions guided by Facilitators from the Community Based Education and Research Services unit within the Community Health Department of Mbarara University of Science and Technology. Priority health training needs were determined based on the computed weighted scores. Results: The majority of managers of rural primary care level health facilities were medical officers by the level of training (51.43\%) and male by gender (68.57\%). Priority health training needs identified were child health and maternal health with total weighted scores of 12.0 and 10.9 respectively. Qualitatively, emerging themes included; leadership and management, and supervisory roles during student field attachments. Conclusion: Priority health training needs at rural Primary Care level health facilities were child health, maternal health, leadership and management, and supervisory skills. There is dire need to train rural primary care level, health professionals. In-service
\end{abstract}


training based on identified needs should be offered by MUST in partnership with regional stakeholders. This is likely to enhance the quality of services provided by rural primary care level health facilities.

\section{Keywords}

Health Training Needs, Rural Health, Rural Medical Education, Continuing Medical Education, Continuous Professional Development, Rural Health Professionals, Primary Care

\section{Introduction}

Continuing Medical Education (CME) is defined as a process of continuous learning to retain, upgrade, and maintain professional competence. It is considered a broad approach to Continuing Professional Development that not only addresses clinical skills but also research and scientific writing, the multidisciplinary context of patient care, professionalism and ethical practice, communication, leadership, management and behavioral skills, team building, information technology, audit, and appropriate attitudinal change. This is aimed at improved patient care service and research outcomes hence better satisfaction degrees by stakeholders [1].

Short courses lasting one to three days have been demonstrated to provide an opportunity for Continuous Professional Development and subspecialty training. Various subspecialties including Primary Trauma Care, Essential Pain Management, and Safer Anaesthesia in Obstetrics and Paediatrics have explored this opportunity. Emphasis is however put on Local ownership for sustainability [2] [3].

A meta-analysis on the effectiveness of CME revealed that small group training which is interactive and using multiple methods had a larger effect size [4]. In South Western Saudi Arabia, Physicians who attended CME activities on Middle East respiratory syndrome coronavirus (MERS-CoV) had excellent knowledge about MERS-CoV [5]. In another meta-analysis, health professionals who had received training were found effective in providing smoking cessation interventions [6].

More than three-quarters of rural General Practitioners in Ireland reported their training needs being met by CME. However, rural General Practitioners have reported several barriers to access CMEs, low morale, and high levels of professional isolation [7]. A study conducted in the United States of America also found that there is a great need for education of first responders and health care providers on military mental health needs [8].

The Uganda Medical and Dental Practitioners Council (UMDPC) have occasionally noted mistakes made by practitioners at different levels and these are attributed to inadequate knowledge and skills, poor attitude, and new technologies. The Medical and Dental Practitioners Statute October 1996 spells out all 
medical and dental practitioners shall undertake CPD as a requirement for renewing the Annual Practicing Licenses [9].

Given the importance of CMEs, WHO recommends that CME programs should be appropriate to the needs of practitioners thus calling for needs assessment in designing the CME courses [1]. This has been done elsewhere in Peru where training needs of CME were obtained from Gastroenterologists [10]. In the bid to build capacity in Global Mental Health, it was recognized that focus should be put on local capacity building in low and middle-income countries [11]. This approach to obtaining local training needs has further been reported elsewhere [12]. It was reported as one of the approaches to improve the effectiveness of Continuing Education for Health Care Professionals since it provides an opportunity for them to initiate, own, and direct their learning [13]. This paper is premised on a theory of Training Needs Analysis (TNA) which involves determining the real training needs which exist. These are then analyzed to identify those that would produce results and appropriate methods of training are used to address them [14] [15] [16].

This study was therefore aimed at identifying priority training needs of primary care level health professionals in rural Western Uganda. This information will guide the development of quarterly CME workshops by Mbarara University of Science and Technology for rural primary care level health professionals in Western Uganda.

\section{Methods}

\section{Design and Health Care Facility Selection}

A descriptive cross-sectional survey integrating both quantitative and qualitative data collection and analysis was conducted. Thirty-five (35) Primary Care Level Heath facilities were represented across 19 districts in Western Uganda. The districts include Mbarara, Mitooma, Ntungamo, Bunyagabu, Bushenyi, Ibanda, Isingiro, Kabale, Kabarole, Kamwenge, Kanungu, Kasese, Kiruhura, Kisoro, Lwengo, Rubanda, Rubirizi, Rukiga and Sheema. Among these, Bunyangabu and Rukiga districts are new districts created in FY 2017/18 [17].

According to the Uganda Bureau of Statistics and the District profiles, the districts have an approximate total area of 28,063.4 sq. km in size and a population of 5,810,672 of which $51 \%$ are female. The population under five and females aged 15 - 44 years constitute $15.3 \%$ and $25 \%$ of the population, respectively. The majority of the population $(82 \%-89 \%)$ resides in rural areas. The wet season in this area occurs in the second and fourth quarters of the year [18].

Uganda's health systems structure is divided into seven levels based on administrative units and the targeted capacity of the catchment population. The health facilities range from Health Centre level one (HC I) to Health Centre Level four (HC IV); General hospital, Regional Referral hospital, and National Referral hospital. The targeted catchment populations for the different levels of health facility vary from 5000 for the level II HC to 500,000 for the general hos- 
pitals. The level I HCs comprise village health teams (VHTs) and have no physical infrastructure. The VHTs facilitate health promotion, service delivery, community participation, and empowerment in access to and utilization of health services [19].

The level II HCs (catchment population 5000) are stand-alone facilities that provide the first level of interaction between the formal health sector and the communities. The level II HCs only provide preventive, promotive and outpatient curative health services, outreach care, and emergency for a parish. They are managed by registered nurses trained at diploma level and these facilities refer patients to level three (HC III) facilities in the sub-county.

The level III HCs (catchment population 20,000) provide preventive, promotive, outpatient curative, maternity, inpatient health services, and laboratory services in a sub-county. They also provide support supervision of the community and the level II HCs under their jurisdiction. Level III HCs have limited inpatient capacity mainly maternity and general patient wards. These facilities are managed by clinical officers at the level of diploma training and they refer patients to level four (HC IV) facilities for further management.

The level IV HCs (catchment population 100,000) provide preventive, promotive, outpatient curative, maternity, inpatient health services, emergency surgery, and blood transfusion and laboratory services at the health sub-district. These facilities are managed by medical officers at a level of bachelor training; patients from these facilities are referred to General hospitals.

The general hospitals (catchment population 500,000) in addition to services provided at Level IV facilities, provide training services, consultation, and operational research in support of the community-based health care programs. There are a total of 1410 healthcare facilities in the western region. General hospitals are managed by Specialists or medical officers and they refer patients to Regional referral hospitals. The majority of the facilities (64\%) are government-owned and the rest are privately owned. By level, the region has 793 HC IIs, 372 HC IIIs, 69 HC IVs, and 35 general hospitals [19].

The selection of the rural health facilities represented was based on the length of collaboration the facility had with the Mbarara University of Science and Technology (MUST) and recommendation by the District Health Officers.

\section{Continuing Medical Education of Primary Care Level Health Professionals}

For more than 25 years, the Department of Community Health in the Faculty of Medicine at MUST annually sends out undergraduate students for field attachments to now more than 50 rural health facilities known as rural community placement sites. This is to support the University's curriculum that is founded on the community-based education philosophy. While in the community, students are based at Community placement sites that are part of the Ministry's health system structure. The health professionals at these facilities take on the mentorship role for the period students spend in the community. They guide them through Community entry, Community diagnosis, Problem identification 
and low-cost health intervention to address the health problem identified.

The Department of Community Health, MUST received funding to build capacity of Primary Care Level Health Professionals through Continuing Medical Education (CME) and continual professional development in its catchment area. Through this arrangement, the Department brings the primary care level health professionals to MUST to be trained in a two-day workshop every quarter. The training is done by different departments in the Faculty of Medicine including Obstetrics and Gynaecology, Internal Medicine, Paediatrics and Child Health, Surgery, family medicine, among others. These pieces of training are aimed at improving service delivery and supervisory capacity of rural community health facilities during Community field attachments for students. Through the District Health Officers (DHOs), Managers of these facilities were invited to MUST for a health training needs assessment at Primary Care level Health Facilities in rural Western Uganda. The DHOs provide leadership of the health sector at the District level.

\section{Instruments, Variables, and Analysis}

To assess the training needs of primary care level health professionals, data collection tools were developed by a team of lecturers from the Community Health Department. Data collection tools were adopted from their experiences from undergraduate student field attachments in the region. These included a self-administered questionnaire and an interview guide. The questionnaire captured data on characteristics of the health facility managers included; gender, age, level of training, health facility type, and level of the health facility. The questionnaire also captured the training needs of each participant. This field required managers to respond in order of priority from priority training need to fifth priority training need.

The interview guide sought responses on areas of training that would improve service delivery and those that would improve their supervision skills for MUST students. Managers of primary health care level facilities were purposively put into small groups of five based on the health facility level. Discussions were guided by facilitators from the Community Based Education and Research Services unit of the Community Health Department of MUST. As an innovation in this study, service providers across the region to share and synthesize training needs at health facilities.

Data was entered in Epidata 3.1 and descriptive statistics of the frequencies and proportions were done using Stata 14 . The response rate was $100 \%$ and there is no bias declared in this study. Respondents generated and ranked priority training needs in the order of first to fifth. We did not include predetermined priority training needs on the tool. We then coded the responses into seven areas; maternal health, child health, rational drug use, infection control, data management, and utilization, leadership and management, and others. The other category included responses like treatment of tuberculosis, HIV treatment, outpatient department services, community research, and clinical services. These 
coded areas were then weighed on the scale of highest 0.5 for the $1^{\text {st }}$ priority and lowest 0.1 for the fifth priority based on the total responses for each level for each priority. The total weighted scores were then used to rank the health priority areas. Qualitative data were coded and thematic areas were generated.

Ethical Consideration: This study was approved by the Research and Ethics Committee of Mbarara University of Science and Technology under approval number 14/11-19 on $12^{\text {th }}$ December 2019.

\section{Results}

Table 1 shows the socio-demographic characteristics of managers of primary care level health facilities and facility ownership $(n=35)$.

Thirty-five managers of rural primary care level health facilities participated in the study. The median age was 35.5 years with Interquartile Range of 9. The majority were male (68.57\%) and majority (51.43\%), medical officers. The majority $(88.57 \%)$ of health facilities represented were Government-owned and Majority (48.57\%) were Health Centre IVs.

Table 2 shows the priority health training needs at primary Care Level health facilities $(\mathrm{N}=35)$.

The highest-ranked priority health training needs were Child health and maternal health with total weighted scores 12.0 and 10.9 respectively.

Qualitatively, facility managers in group discussion raised themes that matched

Table 1. The socio-demographic characteristics of managers of primary care level health facilities and facility ownership ( $\mathrm{n}=35)$.

\begin{tabular}{|c|c|}
\hline Characteristic & $\mathrm{n}(\%), \mathrm{N}=35$ \\
\hline Age (median, IQR) & $(35.5,9)$ \\
\hline \multicolumn{2}{|l|}{ Gender } \\
\hline Male & $24(68.57)$ \\
\hline Female & $11(31.43)$ \\
\hline \multicolumn{2}{|l|}{ Level of facility } \\
\hline Hospital & $2(5.71)$ \\
\hline Health Centre IV & $17(48.57)$ \\
\hline Health Centre III & $16(45.71)$ \\
\hline \multicolumn{2}{|l|}{ Level of training } \\
\hline Medical officer & $18(51.43)$ \\
\hline Clinical officer & $13(37.14)$ \\
\hline Nurse & $4(11.43)$ \\
\hline \multicolumn{2}{|l|}{ Health Facility Type } \\
\hline Public & $31(88.57)$ \\
\hline Private & $1(2.86)$ \\
\hline Private Not For Profit (PNFP) & $3(8.57)$ \\
\hline
\end{tabular}


Table 2. The priority health training needs at primary care level health facilities $(\mathrm{N}=35)$.

\begin{tabular}{|c|c|c|c|c|c|c|}
\hline Training area & $\begin{array}{c}1^{\text {st }} \text { priority } \\
\mathrm{n}(\%)\end{array}$ & $\begin{array}{c}2^{\text {nd }} \text { priority } \\
\text { n (\%) }\end{array}$ & $\begin{array}{c}3^{\text {rd }} \text { priority } \\
\text { n (\%) }\end{array}$ & $\begin{array}{c}4^{\text {th }} \text { priority } \\
\text { n }(\%)\end{array}$ & $\begin{array}{c}5^{\text {th }} \text { priority } \\
\text { n }(\%)\end{array}$ & $\begin{array}{c}\text { Total } \\
\text { weighted } \\
\text { score }\end{array}$ \\
\hline Maternal Health & $15(48.4)$ & $3(9.7)$ & $6(20.0)$ & 0 & $4(19.0)$ & 10.9 \\
\hline Child Health & $5(16.1)$ & $15(48.4)$ & $8(26.7)$ & $4(14.8)$ & $3(14.3)$ & 12.0 \\
\hline Infection control & $2(6.5)$ & 0 & $5(16.7)$ & $1(3.7)$ & $1(4.8)$ & 2.8 \\
\hline Rational Drug use & $1(3.2)$ & 0 & 0 & $2(7.4)$ & 0 & 0.9 \\
\hline $\begin{array}{l}\text { Data management } \\
\text { and utilization }\end{array}$ & 0 & $2(6.5)$ & $1(3.3)$ & $2(7.4)$ & $5(23.8)$ & 2.0 \\
\hline $\begin{array}{l}\text { Leadership and } \\
\text { management }\end{array}$ & 0 & $1(3.2)$ & $2(6.7)$ & $2(7.4)$ & $1(4.8)$ & 1.5 \\
\hline Other & $8(25.8)$ & $10(32.3)$ & $8(26.7)$ & $16(59.3)$ & $7(33.3)$ & 14.3 \\
\hline Total Responses & 31 & 31 & 30 & 27 & 21 & \\
\hline
\end{tabular}

with the ranked priorities. For example, a male medical officer aged 28 mentioned: “... I think our midwives need to be refreshed on Obstetric care”. This was similar to what a female clinical officer aged 35 years reported "I face challenges when handling newborns... especially when they are sick... I just can't proceed".

Other themes that emerged from qualitative data included leadership and management, and supervisory roles of health facility staff during community field attachments for medical students. Under these themes, some health facility staff including managers do not know how to supervise university students during field attachments at their facilities. “... We do not know what to do with students when they are sent to us..." Female, 57, Nurse. This also stretched to areas of Human resource, conflict resolution, and communication skills. “... Most things I do as an in-charge, I learn on job.... If I am trained, I believe I will become a better leader" Male, 52, Clinical Officer.

Overall, managers sought training for themselves and other staff to improve service delivery to both the community and the medical students they receive for field attachment.

\section{Discussion}

Medical Officers dominated leadership of primary care level health facilities represented probably because most facilities were at Health Centre IV level which according to Ministry of health, are supposed to offer emergency operations that are performed by medical officers [19].

The study reports the health training needs at primary care level health facilities in rural Western Uganda that managers think are of the highest priority. Among the priority health training needs reported by managers, child health and maternal health ranked highest. This is likely due to the high demand for services in these areas with many subspecialties requiring ongoing training. Locally 
there is also a high turnover of staff offering maternal and child health services thus posing a need for continual training especially when new and inexperienced staff assume the roles. Additionally, managers also identified the training need for supervisory roles, and leadership and management.

Just like in this study, a great need has been for Continual Professional Education has been expressed among primary care level health professionals elsewhere [20] [21] [22]. In America, training as a tool has been recommended to be accessible and flexible with community-level resources encompassed with educational experiences for community health workers [23]. Additionally, another study in the USA, reported the indisputable need for training and continuing education for Community Health Workers focused at an organizational level [24]. This is in agreement with the findings in this study.

Furthermore, rural health facility managers identify the important area of Leadership and management. This could be explained by the fact that the training curriculum for most of the cadres ( $1^{\text {st }}$ degree or diploma or certificate) in the leadership position does not explore to a great detail practical leadership and management skills (for example conflict resolution, public relations, communication, and financial management). Thus, they learn on the job when deployed to offer leadership at these rural primary care level health facilities making it an important health training need especially for managers. This is consistent with findings elsewhere that revealed supervisory, general communication, and profession-specific training needs [20] [21] [25].

In this study, also managers of rural health facilities represented identified the need for training on supervisory roles during field attachments for medical students. This is in line with the community engagement of MUST that has existed for more than 35 years. This is done through field attachments of undergraduate medical students for four weeks. During such field attachments, students are largely supervised by rural health facility managers as resident supervisors. Mbarara University also sends supervisors (lecturers) one to two times due to limited resources. According to reports of COBERS unit of the Department of community health, rural community health facility supervisors receive training only once in every three years as opposed to the target on once every year due to limited resources. the rural-based training of medical practitioners is done by medical training institutions to positively influence students to choose a rural practice and prioritize community health needs in their career development, research, and innovation [26] [27] [28] [29] [30].

\section{Limitations}

The present study is limited in geographical and sample size representation thus may not be representative of all primary care level health facilities. The study also focuses on facility leaders' perspectives and does not include views of other facility staff like other clinical staff, support staff, and even patients or community members. Further studies in the future may include multiple team members 
to obtain their views on health training needs.

\section{Conclusions}

Medical officers and male gender dominate the leadership of primary care level health facilities in rural Western Uganda. Primary care level health professionals have a variety of health training needs requiring continual education. Highly ranking health training needs were maternal and child health.

In collaboration with other stakeholders, MUST should play a prominent role in the provision of in-service training to health professionals in Primary Care level Health facilities in the region. In-service training should primarily focus on priority areas identified.

These findings allude to the fact that while medical training institutions send students for rural field attachment, they should train the community health facility staff on the supervisory roles and skills to facilitate the rural training of medical trainees.

\section{Availability of Data and Materials}

All data supporting our findings are contained in the paper. There are no restrictions on data sources. This data may be accessed through the corresponding author.

\section{Author's Contribution}

PCK was involved in the conception, design, implementation, data analysis, interpretation of findings, and writing the manuscript. MN, EMM, GS, and DG were involved in the conception of the idea, design, implementation, interpretation of findings, and review of the manuscript. DSA and FB participated in data analysis, interpretation of findings, and review of the manuscript. JK, SB (shem), MM, ACW, DSA, SB (Stephen), MW, and FB participated in the interpretation of results and review of the manuscript.

\section{Acknowledgements}

Authors acknowledge the support of the following individuals; Sarah Mian-McCarthy, Gad Ruzaaza Ndaruhutse, Angella Tumuhimbise, Dennis Tumuramye, Ivan Magomu, Femus Agaba, and Angela Tushabe.

\section{Source of Support}

The study was funded by First Mile Community Health Program, Department of Community Health, Mbarara University of Science and Technology.

\section{Conflicts of Interest}

The authors declare no conflicts of interest regarding the publication of this paper. 


\section{References}

[1] WHO (2010) Regional Guidelines for Continuing Medical Education (CME) Continuing Professional Development (CPD) A Activities. WHO Regional Office for South-East Asia.

[2] Evans, F.M., Duarte, J.C., Loor, C.H. and Morriss, W. (2018) Are Short Subspecialty Courses the Educational Answer? Anesthesia \& Analgesia, 126, 1305-1311. https://doi.org/10.1213/ANE.0000000000002664

[3] Kyrkjebø, J.M., Brattebø, G. and Smith-Strøm, H. (2006) Improving Patient Safety by Using Interprofessional Simulation Training in Health Professional Education. Journal of Interprofessional Care, 20, 507-516. https://doi.org/10.1080/13561820600918200

[4] Mansouri, M. and Lockyer, J. (2007) A Meta-Analysis of Continuing Medical Education Effectiveness. Journal of Continuing Education in the Health Professions, 27, 6-15. https://doi.org/10.1002/chp.88

[5] Al-Amri, S., Bharti, R., Alsaleem, S.A., Al-Musa, H.M., Chaudhary, S. and Al-Shaikh, A.A. (2019) Knowledge and Practices of Primary Health Care Physicians Regarding Updated Guidelines of MERS-CoV Infection in Abha City. Journal of Family Medicine and Primary Care, 8, 455.

https://doi.org/10.4103/jfmpc.jfmpc_336_18

[6] Lancaster, T. and Fowler, G. (2000) Training Health Professionals in Smoking Cessation. Cochrane Database of Systematic Reviews, No. 3, CD000214. https://doi.org/10.1002/14651858.CD000214

[7] Dowling, S., Last, J., Finnegan, H., O’Connor, K. and Cullen, W. (2019) Does Locally Delivered Small Group Continuing Medical Education (CME) Meet the Learning Needs of Rural General Practitioners? Education for Primary Care, 30, 1-7. https://doi.org/10.1080/14739879.2019.1573109

[8] Baier, A.L., Marques, L., Borba, C.P.C., Kelly, H., Clair-Hayes, K., Dixon De Silva, L., et al. (2019) Training Needs among Nonmental Health Professionals Working with Service Members: A Qualitative Investigation. Military Psychology, 31, 71-80. https://doi.org/10.1080/08995605.2018.1541392

[9] (UMDPC) UMaDPC (2017) Continuing Professional Development (CPD) Accreditation and Certification Guidelines.

[10] Castillo, O.C., Sandoval, M.V., Díaz, J.F. and Soriano, C.Á. (2018) Perception of the Gastroenterologist about the Needs of Continuing Medical Education in Peru. Revista de gastroenterologia del Peru: Organo oficial de la Sociedad de Gastroenterologia del Peru, 38, 356-364.

[11] Fricchione, G.L., Borba, C.P., Alem, A., Shibre, T., Carney, J.R. and Henderson, D.C. (2012) Capacity Building in Global Mental Health: Professional Training. Harvard Review of Psychiatry, 20, 47-57. https://doi.org/10.3109/10673229.2012.655211

[12] Lurie, S. (2005) Identifying Training Needs of Health-Care Providers Related to Treatment and Care of Transgendered Patients: A Qualitative Needs Assessment Conducted in New England. International Journal of Transgenderism, 8, 93-112. https://doi.org/10.1300/J485v08n02_09

[13] Griscti, O. and Jacono, J. (2006) Effectiveness of Continuing Education Programmes in Nursing: Literature Review. Journal of Advanced Nursing, 55, 449-456. https://doi.org/10.1111/j.1365-2648.2006.03940.x

[14] Boydell, T. (1976) The Identification of Training Needs. British Association for Commercial and Industrial Education. Grosvenor Press, Portsmouth. 
[15] Goldstein, I.L. and Ford, K. (1993) Training in Organizations: Needs Assessment, Development, and Evaluation. Brooks. Cole Publishing Company, Pacific Grove.

[16] Williamson, M. (1993) Training Needs Analysis. UNIPUB, Lanham.

[17] Health Mo (2018) Annual Health Sector Performance Report 2017/18. Report, Management P, Kampala.

[18] UBOS (2019) Statistical Abstract.

[19] Health Mo (2019) National Health Facility Master List 2018. Health Facility Inventory. MoH, Kampala.

[20] Gaspard, J. and Yang, C.-M. (2016) Training Needs Assessment of Health Care Professionals in a Developing Country: The Example of Saint Lucia. BMC Medical Education, 16, Article No. 112. https://doi.org/10.1186/s12909-016-0638-9

[21] Hemm, C., Dagnan, D. and Meyer, T.D. (2015) Identifying Training Needs for Mainstream Healthcare Professionals, to Prepare Them for Working with Individuals with Intellectual Disabilities: A Systematic Review. Journal of Applied Research in Intellectual Disabilities, 28, 98-110. https://doi.org/10.1111/jar.12117

[22] Story, M.T., Neumark-Stzainer, D.R., Sherwood, N.E., Holt, K., Sofka, D., Trowbridge, F.L., et al. (2002) Management of Child and Adolescent Obesity: Attitudes, Barriers, Skills, and Training Needs among Health Care Professionals. Pediatrics, 110, 210-214.

[23] Klimmek, R.K., Noyes, E., Edington-Saunders, K., Logue, C., Jones, R. and Wenzel, J. (2012) Training of Community Health Workers to Deliver Cancer Patient Navigation to Rural African American Seniors. Progress in Community Health Partnerships: Research, Education, and Action, 6, 167. https://doi.org/10.1353/cpr.2012.0017

[24] Allen, C., Brownstein, N., Satsangi, A. and Escoffery, C. (2016) Capacity Building and Training Needs for Community Health Workers Working in Health Care Organizations. Journal of Community Medicine and Health Education, 6, 403. https://doi.org/10.4172/2161-0711.1000403

[25] Sarre, S., Maben, J., Aldus, C., Schneider, J., Wharrad, H., Nicholson, C., et al. (2018) The Challenges of Training, Support and Assessment of Healthcare Support Workers: A Qualitative Study of Experiences in Three English Acute Hospitals. International Journal of Nursing Studies, 79, 145-153. https://doi.org/10.1016/j.ijnurstu.2017.11.010

[26] Barrett, F.A., Lipsky, M.S. and Lutfiyya, M.N. (2011) The Impact of Rural Training Experiences on Medical Students: A Critical Review. Academic Medicine, 86, 259-263. https://doi.org/10.1097/ACM.0b013e3182046387

[27] Jensen, C.C. and DeWitt, D.E. (2002) The Reported Value of Rural Internal Medicine Residency Electives and Factors That Influence Rural Career Choice. The Journal of Rural Health, 18, 25-30. https://doi.org/10.1111/j.1748-0361.2002.tb00872.x

[28] Lacy, N.L., Paulman, P.M. and Hartman, T.L. (2005) The Effect of Preceptorship Rurality on Students' Self-Perceived Clinical Competency. Family Medicine, 37, 404-409.

[29] Patterson, D.G., Andrilla, C.H.A. and Garberson, L.A. (2019) Preparing Physicians for Rural Practice: Availability of Rural Training in Rural-Centric Residency Programs. Journal of Graduate Medical Education, 11, 550-557. https://doi.org/10.4300/JGME-D-18-01079.1

[30] Worley, P., Esterman, A. and Prideaux, D. (2004) Cohort Study of Examination Performance of Undergraduate Medical Students Learning in Community Settings. BMJ, 328, 207-209. https://doi.org/10.1136/bmj.328.7433.207 


\section{Acronyms and Operational Definitions}

$\begin{array}{ll}\text { CME } & \text { Continuing Medical Education } \\ \text { COBERS } & \text { Community Based Education and Research Services } \\ \text { CPD } & \text { Continous Professional Development } \\ \text { DHO } & \text { District Health Officer } \\ \text { HC } & \text { Health Centre } \\ \text { MERS-CoV } & \text { Middle East respiratory syndrome Coronavirus } \\ \text { MUST } & \text { Mbarara University of Science and Technology } \\ \text { TNA } & \text { Training Needs Analysis } \\ \text { UMDPC } & \text { Uganda Medical and Dental Practitioners Council }\end{array}$

Training: In this context training refers to the teaching of health care workers in lower-level health facilities to increase knowledge and skills to retain, upgrade, and maintain professional competence. This is done by the university teaching staff.

Health care workers: In this context health care professionals include midwives, nurses, laboratory technicians, records assistants, health information assistants, clinical officers, medical officers, among others. 